\title{
Until We Meet Again
}

\section{Rich Snow* and Mary Snow}

Professors of Meteorology, Embry-Riddle Aeronautical University, USA

*Corresponding Author: Rich Snow, Professor of Meteorology, Embry-Riddle Aeronautical University, USA; Tel: 386-226-7104; E-mail: snow4fc@erau.edu Received date: Jul 25, 2016; Accepted date: Jul 26, 2016; Published date: Jul 29, 2016

Copyright: (c) 2015 Snow R, et al. This is an open-access article distributed under the terms of the Creative Commons Attribution License, which permits unrestricted use, distribution, and reproduction in any medium, provided the original author and source are credited.

\section{Editorial}

As long ago as 1896, Svanti Arrenius conducted a scientific analysis of the relationship between carbon dioxide $\left(\mathrm{CO}_{2}\right)$ and atmospheric temperatures. Several decades later, GS Callender collected and compiled temperature data from around the world and found there had been an increase in global temperatures. He hypothesized that the rising temperatures were resulting from increasing levels of $\mathrm{CO}_{2}$. These early studies piqued the interest of Gilbert Plass in the mid-20th century who endeavored to determine how $\mathrm{CO}_{2}$ affects temperature. In his effort to determine the possible effects that higher levels of $\mathrm{CO}_{2}$ in the atmosphere were having on the energy flux, Plass found that $\mathrm{CO}_{2}$ molecules are efficient absorbers of Earth's outgoing heat energy. Higher levels of carbon dioxide cause greater absorption of outgoing heat energy, less heat escapes to space, and higher atmospheric temperatures result. In 1956, Plass presented his theory and from his analysis the term greenhouse effect entered the lexicon of climatology. Six decades have passed since Plass presented his work to the scientific community. Each and every year since, $\mathrm{CO}_{2}$ levels have increased. Every decade since has been hotter than the previous decade. June 2016 marked 371 consecutive months with a monthly mean that was at or above the normal average for that month. The last monthly mean that was below average occurred in 1985, 31 years ago.

The effects of global warming are manifesting themselves in countless ways as coastal communities in Alaska and small island nations are displaced; as we lose species of amphibians and mammals to rampant growth of fungi that thrive in higher humidity; as the number of severe weather events increases along with the wind speeds associated with these storms; as the oceans acidify causing the calcium carbonate shells of the foraminifera to disintegrate and those marine creatures die; as the absence of a cold snap in the winter allows bark beetles to proliferate and destroy millions of acres of spruce forest; as higher temperatures speed up the metabolism of mosquitoes causing their rate of biting to increase; as permafrost in the tundra melts releasing methane which is a potent greenhouse gas; and as Greenland, the Arctic, and alpine glaciers melt precipitously. So the question becomes, in light of all the data and empirical evidence that clearly demonstrate global warming is occurring, why are the world's leaders not taking action?

A brief review of some of the conferences designed to mitigate global climate change include the Rio de Janeiro Earth Summit which was held June 3-14, 1992. There were 172 governments represented and more than 10,000 journalists were on site to bring the discussions to millions of people around the world. The themes were sustainable development, unconstrained consumption by the affluent, and the destruction of irreplaceable natural resources. The take home message from the Rio Earth Summit was that nothing less than a paradigmatic shift in our attitudes and behaviour would bring about the change necessary to avoid the worst impacts on the environment and to curtail the present devastation of ecosystems.

Then there was the Kyoto Protocol which was an international treaty that built upon the 1992 United Nations Framework Convention on Climate Change (UNFCCC). National leaders convened in Kyoto, Japan, in December 1997. The treaty was founded on the notion that global warming exists and that anthropogenic $\mathrm{CO}_{2}$ emissions have caused it. Many heads of states agreed to reduce their greenhouse gases emissions to various percentages below 1990 levels. Several developed countries refused to sign the agreements, including Canada and the United States. Later, when Iceland and Russia endorsed the protocol, it was ratified. However, its target emissions were not mandatory nor legally binding. In 2013, global carbon emissions were 60\% higher than 1990 levels.

Another notable convention occurred in 2009. The United Nations Climate Change Conference was held in Copenhagen, Denmark, from December 7-18. The "Hopenhagen" Summit included the 15th Conference of the Parties (COP 15) to the United Nations Framework Convention on Climate Change and the 5th Meeting of the Parties (MOP 5) to the Kyoto Protocol. A framework for climate change mitigation beyond 2012 was to be forged in Copenhagen. On the last day of the conference, journalists from around the world reported that the climate talks were "in disarray" Media also reported that rather than a complete summit collapse, only a "weak political statement" was expected at the close of the conference. U.N. secretary-general Ban Kimoon explained at the summit, "Climate change is one of the epic challenges facing this and future generations. It is time to seal a deal. We need a global movement that mobilizes real change". He added, "Hopenhagen is about global action for a global climate treaty and a better future for humankind".

The summit culminated in the Copenhagen Accord which was judged a "meaningful agreement" by the United States government. The following day, in the concluding deliberations by the 192 U.N. delegates and other participants, the accord was "taken note of," but not "adopted". The document acknowledged Ban Ki-moon's words stating that climate change is one of the greatest challenges of the present day and added that steps should be taken to keep temperature increase below $2^{\circ} \mathrm{C}$ compared with pre-industrial levels. The document is not legally binding and does not contain any concrete commitments for reducing $\mathrm{CO} 2$ emissions. The $2^{\circ} \mathrm{C}$ threshold is described by the foremost authorities on global warming as the "tipping point." At this point, the climate system goes non-linear and is far less predictable. Positive feedback loops would be unleashed including melting Arctic sea ice, which in turn exposes darker ocean water allowing it to absorb (rather that reflect) solar radiation, further heating the Arctic Ocean, thereby melting more sea ice. An increase of $2^{\circ} \mathrm{C}$ has been estimated by the U.N. to give rise to 800 million climate refugees from coastal inundation, prolonged droughts, reduced crop yields, and fresh water shortages in conjunction with severe flooding. 
Page 2 of 2

Several years have passed since Copenhagen, billions more tons of $\mathrm{CO} 2$ have been added to the atmosphere and oceans, and more conferences have ensued. The most recent meeting in Paris was held from November 30-December 12, 2015. This U.N. Climate Change Conference marked the 21st annual session of the Conference of the Parties (COP 21) to the 1992 UNFCCC, and it was the 11th session of the Meeting of the Parties (MOP 11) to the 1997 Kyoto Protocol. At the start of the talks, the organizing committee stated that the expected key result was an agreement that would set a goal of limiting global warming to less than $2^{\circ} \mathrm{C}$ (compared to pre-industrial levels). The heads of state and other attendees, such as representatives from numerous NGOs, negotiated the Paris Agreement, which is a global agreement to reduce climate change. This document represents a consensus of the 196 attending parties and would go into effect when joined by at least 55 countries which together emit at least $55 \%$ of global greenhouse gases. On April 22, 2016 (Earth Day), 174 countries signed the agreement in New York and began adopting it through either ratification, acceptance, approval, or accession, according to their legal system. The Paris Agreement calls for zero net human-made greenhouse gas emissions to be reached during the second half of the 21st century. In the version of the Paris Agreement that was finally adopted, the parties will also "pursue efforts to" limit the temperature increase to $1.5^{\circ} \mathrm{C}$. The $1.5^{\circ} \mathrm{C}$ goal will require zero emissions sometime between 2030 and 2050, according to some scientists.

For the past million years, CO2 ranged from 170 to 280 parts per million (ppm) as Earth passed through roughly a half dozen glacial and interglacial cycles within the larger Ice Age, or Pleistocene Epoch. During the past couple of years, we crossed the $400 \mathrm{ppm}$ threshold for CO2. For mid-July, 2016, CO2 rang in at $404 \mathrm{ppm}$. We also crossed the $1.0^{\circ} \mathrm{C}$ mark of global average annual temperatures above pre-industrial levels. The world's ocean heats more slowly, but it has warmed by an average of $0.6^{\circ} \mathrm{C}$ to a depth of approximately 10,000 feet. So, the $1.0^{\circ} \mathrm{C}$ warming of the atmosphere does not include the heat that will be released from the oceans, which is another $0.5^{\circ} \mathrm{C}$ by the year 2100 . Neither does the current degree of warming include heating that will occur from the lingering effects of the greenhouse gases we emit today. $\mathrm{CO} 2$, for example, has a residence time of approximately 100-150 years, so the $\mathrm{CO} 2$ emitted today will continue to warm the atmosphere into the next century.

It was reported recently that the world's ocean is reaching the point of saturation in terms of its $\mathrm{CO} 2$ content such that soon it will no longer be able to take up $\mathrm{CO} 2$ from the atmosphere. Presently, the oceans provide a "sink," or reservoir, for $\mathrm{CO} 2$ as they take up approximately a quarter of the $\mathrm{CO} 2$ that we emit, as does terrestrial vegetation. Yet we continue to slash and burn rainforest to produce more beef (largely for affluent societies), more sugar cane, and palm oil. As we remove and despoil our natural "sinks" for $\mathrm{CO} 2$, we emit ever greater quantities of it as well as methane.

Presently in the United States, the campaign for president races forward. Of the two leading candidates, one claims that climate change is a "con job" and a "myth." There are currently members of Congress who vow that immediately following this election they will disregard U.S participation in the Paris Agreement. These same leaders intend to overturn the Clean Power Plan as well, which was wrought over two years by the present administration and the Environmental Protection Agency (EPA) to provide direction toward a sustainable future grounded in renewable energies. The future of the world's leading superpower and one of its largest emitters of greenhouse gases hangs in the balance.

As a nation, the U.S. desperately needs leadership that is accountable to the people, not one that acquiesces to the demands of corporations with a vested interest in fossil fuels. The world's wealthiest corporations are literally allowed to write the legislation that governs them, and the groups they support have a stranglehold on legislators whose campaigns they finance as well as media outlets that they sponsor. Research institutions are not immune to their influence either. To make democracy work, we need an informed citizenry, high voter turnout, and leaders who are not beholden to the highest bidder. Other countries are watching and waiting for the U.S. to lead by example. We cannot do that if we are constrained to corporate whim and restrained by their undue influence.

In 2010, CO2 was labeled a pollutant by the EPA. As such, polluters should pay for dumping their waste into our atmosphere. No other industry, nor household for that matter, is allowed to dispose of its waste without a fee. In parts of the U.K., there is a fee exacted of approximately $\$ 20$ (U.S.) per ton of $\mathrm{CO} 2$ emitted. Some say the fee would be passed on to the consumer. Others show that a dividend check issued to each legal citizen at the end of each month would pay for the higher cost imposed on the people by the industry. If polluters were made to pay to pollute, they would undoubtedly pollute less. They would scramble to develop the latest renewable energies, mass production would drive down costs, and millions of clean jobs would be created. We have had enough conferences and meetings. We know what needs to be done. We simply need leadership with courage to challenge the status quo, cease subsidizing polluters, and make them pay their fair share while mitigating climate change. 